\title{
Rapid Diagnosis of Tuberculous Pleural Effusion by IS6110 Sequence Based PCR
}

\author{
Dr.G.Kalaiselvi ${ }^{1}$, Dr.K.Rajendran ${ }^{2}$ \\ Associate Professor, Department of Microbiology, Annapoorana Medical College And Hospital, Salem, India \\ Professor and H.O.D., Department of Microbiology, Coimbatore Medical College, Coimbatore, India
}

\begin{abstract}
Diagnosis of EPTB has always been a challenge. PCR-based assays using the insertion-like sequence element IS6110 have shown considerable promise in clinical studies. The present study was undertaken to evaluate the role of PCR in the laboratory diagnosis of Tuberculous pleural effusion in comparison to conventional bacteriological techniques in Indian settings. One hundred and five, non- repeated clinical samples from patients who fulfilled the inclusion criteria were collected and were processed for Ziehl-Neelsen $(Z N)$ staining for acid fast bacilli (AFB) and culture on Lowenstein-Jensen medium and Middle brook $7 H 9$ medium. All the sampled were also processed for IS6110 based PCR amplification with primers targeting 123 bp fragment of insertion element IS6110 of the M.tuberculosis complex. Of these 105 samples, four (3.8\%) were positive for acid fast bacilli by ZN staining, 21(20\%) were positive for Mycobacteria by Culture and 73 (70\%) were positive for M.tuberculosis complex by IS6110 based PCR. Our studies reveal that the IS6110 based PCR methodology for the detection of the M. tuberculosis complex in the pleural fluid is a highly sensitive, specific and reproducible method for early diagnosis of TPE. PCR targeting IS6110 can be applied when there is strong clinical suspicion, especially when the conventional techniques are negative.
\end{abstract}

Key words: Acid fast bacilli, Extra pulmonary tuberculosis, Mycobacterium tuberculosis, Non - tuberculous Mycobacterium, Polymerase chain reaction, Tuberculous pleural effusion

\section{Introduction}

Tuberculosis became a problem with the emergence of HIV/AIDS pandemic, because HIV not only reactivates a latent infection but also makes the disease more serious and treatment ineffective. Another factor that has made the situation graver is the emergence of multidrug resistant tuberculosis (MDR-TB) as well as extensively drug resistant tuberculosis (XDR-TB) Reported global annual incidence of TB cases estimate is 9.4 million cases, out of which it is estimated that 1.8 million cases are from India. ${ }^{[1]}$ The global increase is believed to be fuelled by the HIV related immune competence, more than $50 \%$ of the HIV positive individual with tuberculosis have had extra pulmonary presentation, while its prevalence is $15-20 \%$ in immunocompromised individuals. Extra pulmonary TB (EPTB) is a significant health problem in both developing and developed countries. ${ }^{[2]}$

Tuberculosis of the pleura is considered to be one among the severe form of extra pulmonary tuberculosis. It can occur alone or in combination with the pulmonary variety. ${ }^{[3]}$ Pleural effusion caused by $\mathrm{M}$. tuberculosis occurs in approximately $30 \%$ of patients with tuberculosis. ${ }^{[4]}$ Diagnosis of EPTB has always been a challenge. The non-availability of technically simple, reliable, rapid and reproducible test often makes the diagnosis difficult. The traditional method of Mycobacterial culture, though considered as a gold standard is less sensitive and takes several weeks to become positive. In paucibacillary situations like tuberculous pleurisy even the sensitivity of smear examination is very low.

In circumstances where smear and culture are negative but when the clinical suspicion is high and corroborative evidences such as radiological and biochemical analysis of pleural fluid are apparent, other reliable tests with increased sensitivity may be needed. The recent demonstration that nucleic acid amplification techniques are rapid and sensitive has modified strategies for the detection of Mycobacterium tuberculosis. ${ }^{[5]}$ Since the application of the polymerase chain reaction (PCR) in the diagnosis of tuberculosis by Brisson et al., PCR diagnostic protocols using varying methods of DNA purification and different $\mathrm{M}$. tuberculosis target sequences have been evaluated. ${ }^{[6],[7],[8],[9],[10],,[11]}$ Among these target sequences, PCR-based assays using the insertion-like sequence element IS6110 have shown considerable promise in clinical studies.IS6110-PCR is a more rapid, sensitive and specific in comparison to other methods routinely used in clinical laboratories.

The present study was undertaken to evaluate the role of PCR in the laboratory diagnosis of tuberculous pleural effusion in comparison to conventional bacteriological techniques in Indian settings

1.1. PCR strategy targeting IS 6110: Detection of Mycobacterial DNA by PCR has the advantage of increased sensitivity and specificity. It has been suggested that those systems that amplify DNA sequences present in multiple copies are more sensitive than those that amplify targets present in a single copy. PCR using the 
IS6110 repetitive sequence as a probe is considered the gold standard for typing M. tuberculosis. IS 6110 is a 355 - bp repetitive insertion sequence that displays variability both in the copy number (from 0 to 25 ) and chromosomal position. ${ }^{[12]}$ This repetitive target increases the sensitivity of assay allowing detection of smaller number of bacilli in paucibacillary TPE

\section{Materials and Methods}

2.1Study design: The study was performed prospectively in a blinded manner in the Department of Microbiology.

2.2. Clinical specimens and data collection: All the Patients who were clinically diagnosed as pleural effusion were considered for the study. Those patients who fulfilled the following inclusion criteria were included as study population

\subsection{Inclusion criteria:}

* Radiological evidence of pleural effusion with or without pulmonary infiltrates

* Ultrasound and C.T scan (Thorax) evidence of pleural effusion.

* Biochemical analysis of pleural fluid demonstrated straw coloured fluid, total count more than 500 cells $/ \mathrm{mm}^{3}$, lymphocytic predominance $(>80 \%)$ and pleural fluid glucose concentration $<40 \mathrm{mg} / \mathrm{dl}$, protein concentrations of $4 \mathrm{mg} / \mathrm{dl}$ (or more)

One hundred and five, non- repeated clinical samples from patients who fulfilled the above criteria were collected with due informed consent. The clinical history regarding present and past history of anti tubercular treatment (ATT), family history of tuberculosis and any other associated disease were taken in prescribed Performa. Among the 105 cases, 40 (38\%) cases were unilateral PT with effusion, $10(9.5 \%)$ cases were patients with bilateral PT with effusion and $55(52.5 \%)$ cases were pleural effusion without pulmonary lesion.

2.4. Sample collection: Under strict aseptic precautions, about $20 \mathrm{ml}$ of pleural fluid was collected and distributed into four sterile anticoagulated screw capped bottles. First sample was utilized for biochemical analysis and looked for glucose, protein and chloride. Second sample was utilized for cytology and cell count such as total count and differential count. Third sample was utilized for bacteriological examination: Grams stain, AFB stain, bacterial Culture and Mycobacterial culture were done. Fourth sample was stored at $-20^{\circ} \mathrm{c}$ for PCR.

2.5. Sample processing: Pleural fluid samples were centrifuged at 3,000 rpm for 15 minutes and the deposit was processed for Gram staining, Ziehl-Neelsen staining for AFB, aerobic culture and culture for M. tuberculosis as per the standard bacteriological procedure. ${ }^{[13]}$ Briefly, a portion of the deposit after digestion was inoculated directly into plain Lowenstein-Jensen (LJ) medium and Lowenstein-Jensen medium with sodium pyruvate (LJP). Another portion was inoculated into Middle brook 7H9 medium and after incubation for six weeks was subcultured onto LJ and LJ-P media. The growth after eight weeks of incubation, if appeared was confirmed to be M. tuberculosis, based on slow growth rate, absence of pigmentation, Niacin test positivity and absence of growth on LJ medium with p-nitrobenzoic acid. Standard strain M. tuberculosis complex, H37Rv ATCC ${ }^{\text {TM No. }}$ 27294 was used as positive control.

2.6. Extraction of DNA from clinical samples: Extraction of DNA was done by the CTAB (cetyl-tri-methylammonium bromide)-phenol chloroform extraction method. ${ }^{[14]}$ Specimens were centrifuged at $10,000 \mathrm{rpm}$ for $10 \mathrm{~min}$. The supernatant was discarded and the pellet suspended in $567 \mu \mathrm{l}$ of TE (Tris EDTA, pH 7.4) buffer, 30 $\mu 110 \%$ SDS (sodium dodecyl sulfate) and $3 \mu \mathrm{l}$ proteinase $\mathrm{K}(20 \mathrm{mg} / \mathrm{ml})$, mixed and incubated at $20^{\circ} \mathrm{C}$ for $1 \mathrm{~h}$. After incubation, $100 \mu \mathrm{l}$ of $5 \mathrm{M} \mathrm{NaCl}$ and $80 \mu \mathrm{l}$ of high-salt CTAB buffer (containing $4 \mathrm{M} \mathrm{NaCl}, 1.8 \% \mathrm{CTAB}$ ) were added and mixed followed by incubation at $65^{\circ} \mathrm{C}$ for $10 \mathrm{~min}$. An approximate equal volume $(0.7-0.8 \mu \mathrm{l})$ of chloroform-isoamyl alcohol (24:1) was added, mixed thoroughly and centrifuged for 4-5 min in a micro centrifuge at $12,000 \mathrm{rpm}$. The aqueous viscous supernatant was carefully decanted and transferred to a new tube. An equal volume of phenol: Chloroform-isoamyl alcohol (1:1) was added followed by a 5 min spin at 12,000 rpm. The supernatant was separated and then mixed with 0.6 volume of isopropanol to get a precipitate. The precipitated nucleic acids were washed with $75 \%$ ethanol, dried and re-suspended in $100 \mu$ of TE buffer.

2.7. Oligonucleotide primers: IS6110 is an 1191-bp repetitive insertion sequence that is usually present 6-20 times in the M. tuberculosis complex genome although as few as one copy has been observed. ${ }^{[15]}$ Amplification of DNA was performed with primers IS-F- 5'-CCTGCGAGCGTAGGCGTCGG-3'and IS-R5'CTCGTCCAGCGCCGCTTCGG-3', to amplify $123 \mathrm{bp}$ fragment of insertion element IS6110 of $M$. tuberculosis complex as reported earlier. ${ }^{[15]}$ 
2.8. DNA amplification by polymerase chain reaction: PCR was carried out in $50 \mu \mathrm{L}$ volume, using $200 \mu \mathrm{M}$ dNTPs, 20pM of each primer and $1 \mathrm{U}$ of Taq polymerase, followed by template. Conditions followed were initial denaturation at $94^{\circ} \mathrm{C}$ for four minutes, followed by 35 cycles at $90^{\circ} \mathrm{C}$ for one minute, $60^{\circ} \mathrm{C}$ for one minute, and $72^{\circ} \mathrm{C}$ for one minute, and a final extension at $72^{\circ} \mathrm{C}$ for 10 minutes. The amplified products were subjected to electrophoresis on a $2 \%$ agarose gel containing ethidium bromide and the results were documented [Fig. 1]. The presence of $123 \mathrm{bp}$ fragment indicates the positive test for M. tuberculosis complex. Throughout the PCR processing the three room procedure and other recommended stringent precautions were followed and the results were evaluated in the light of the performance of appropriate positive and negative controls, to avoid cross-contamination and false positive reactions. The positive controls included the DNA of H37Rv strain. Negative control included PCR grade water.

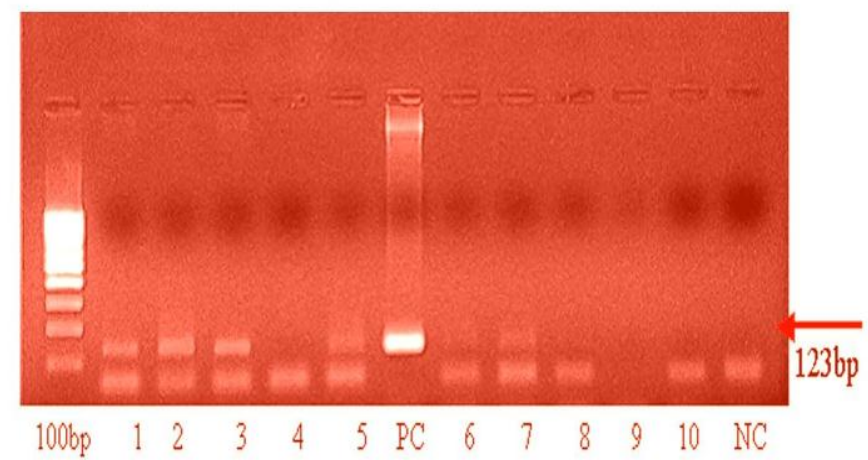

Fig. 1: A 123 bp fragment of the M. tuberculosis amplified by PCR with primers IS 6110 among the samples of TPE, PC - Positive control; NC - Negative control; 100 bp - Molecular weight marker Lanes 1, 2, 3, 5, 6, 7samples positive for IS6110 sequence

\section{Results}

3.1. Demographic profile: In the evaluation of the demographic characteristics of the 105 patients, maximum cases were recorded in the age group between 20 and 50yrs. In the study, $71(67.7 \%)$ were males and 34 $(32.3 \%)$ were females with a ratio of $2: 1$ (Table: 1$)$. Co morbid conditions were found in $48(46 \%)$ patients. The history of contact with TB patients was determined in 3 cases, 10 were having the history of Diabetes mellitus, family history of TB were present in 3 cases, other co morbid conditions like smoking, alcohol and overcrowding were recorded in 32 cases and 3 cases were positive for HIV antibody by ELISA.

Table 1: Age and Sex distribution of clinically diagnosed TPE $(\mathbf{N}=105)$.

\begin{tabular}{|l|l|l|l|}
\hline Age & Male & Female & Total \\
\hline$<20 \mathrm{yrs}$ & 6 & 4 & 10 \\
\hline $20-50 \mathrm{yrs}$ & 49 & 25 & 74 \\
\hline$>50 \mathrm{yrs}$ & 16 & 5 & 21 \\
\hline
\end{tabular}

3.2. Bacteriological profile: Gram stain and bacterial cultures of the 105 pleural fluid samples were negative. Four out of the 105 samples (3.8\%) were smear positive for AFB. Culture for AFB showed positive in 21(20\%) samples among the 105 samples processed. Among the 21 culture positive cases, 19 cases (90\%) were Mycobacterium tuberculosis and 2 cases (10\%) were NTM (Scotochromogens). Either smear or culture for AFB was found positive in $22(21 \%)$ of the total 105 samples investigated. (Table: 2$)$

Table 2: Bacteriological profile of clinically diagnosed TPE $(n=105)$

\begin{tabular}{|l|l|l|l|}
\hline \multicolumn{1}{|c|}{ Category } & Culture positive & Smear positive & Smear negative \\
\hline Mycobacterium tuberculosis (19) & 19 & 3 & 16 \\
\hline Non Tuberculous Mycobacteria (2) & 2 & 0 & 2 \\
\hline Culture negative (84) & 0 & 1 & 83 \\
\hline
\end{tabular}


3.3. Molecular profile: PCR was positive in 73 out of 105 samples (69.5\%). PCR alone was positive in 53 $(51 \%)$ among 85 samples that were negative by both the conventional bacteriological techniques such as smear and culture for AFB. (Table: 3) Analysis of PCR results among samples positive by conventional methods showed that the one sample positive for AFB smear and 19 samples positive for AFB culture were positive by PCR. Both the Non -Tuberculous Mycobacteria were negative by PCR. Remaining the 20 samples which were positive by either smear or culture for AFB was positive by PCR. Thus conventional bacteriological techniques were positive in $21 \%$ of samples whereas PCR was positive in $70 \%$ of samples. This suggested that the PCR assay was more sensitive compared to conventional tests.

\section{Table 3: Results of PCR}

\begin{tabular}{|l|l|l|l|l|}
\hline Category & S+C+ & S+C- & S-C+ & S-C- \\
\hline Number of cases & 3 & 1 & 16 & 85 \\
\hline PCR Positive & 3 & 1 & 16 & 53 \\
\hline
\end{tabular}

\section{Discussion}

Tuberculosis, "the captain of all the men of death", a re-emergent killer, threatening to assume serious proportions all over the world. So serious is the global threat of tuberculosis WHO in 1993 took the unprecedented step of declaring this disease, a global emergency. ${ }^{[16]}$ Extra Pulmonary tuberculosis is increasing worldwide. One of the common sequelae of pleural effusion caused by M. tuberculosis is residual pleural thickening. Fibrothorax, Empyema thoracis, Empyema necessitans, pneumothorax, and pyopneumothorax are other complications. ${ }^{[17]}$ In the scenario of global resurgence of tuberculosis a rapid, sensitive and cost effective diagnostic test would aid in early diagnosis and prompt initiation of appropriate treatment there by limiting the spread of infection especially in the developing countries where vast majority of cases occur.

PCR is the rapid and sensitive method for the detection of Mycobacterial DNA in TPE (Nagesh et.al. 2001).It can amplify even a single bacilli present in paucibacillary TPE.In aspirates from tuberculous pleural effusion, organisms are rarely seen following $\mathrm{ZN}$ microscopy because of paucibacillary nature of the disease. In our study we have encountered only $4(3.8 \%) \mathrm{ZN}$ positive cases. Among the four, 3 were culture positive and one was culture negative. The culture negative case may be due to the presence of non-viable mycobacterium in partially treated patients or due to harsh chemical treatment used in decontamination. ${ }^{[18]}$

In our study Mycobacterial culture, though considered as the "Gold Standard" was positive only in $20 \%$ of patients. Previous series of patients with tuberculous pleural effusion describe pleural fluid that is culture-positive in as few as 13 percent to as many as 70 percent of patients. ${ }^{[3],[19],[20],[21]}$ The low sensitivity of the culture in the pleural fluid was also demonstrated in a study done by Berger and Mejia et. al., who verified that in the pleural fluid cultures, it is only possible to detect the presence of the M. tuberculosis in $20-30 \%$ of infected patients. ${ }^{[19]}$ In another study done by SK Katiyar and RP Singh et. al., culture was positive only in $19.05 \%$ of cases. Direct examination of pleural fluid and ZN staining requires bacillary concentration of more than $10,000 / \mathrm{ml}$ and therefore has a low sensitivity. Although culture is more sensitive, it requires a minimum of 10 viable bacilli /ml. In our study all culture positive and smear positive samples were PCR positive. 2 NTM samples were also subjected to PCR but the PCR results were negative because the primers used were specific for M. tuberculosis. Among the 85 culture negative samples PCR was positive in 53 samples. PCR was positive overall in 73 samples $(70 \%)$.

Previous studies reported ${ }^{[22[,[23],[24], 125]}$ the increased positivity by PCR targeting the IS6110 element in specimens of EPTB and $62 \%, 73 \%, 77 \%$ and $90 \%$ as positivity among EPTB specimens. Also a recent Indian study by Negi el al on comparison of different PCR protocols, targeting different gene sequences of $\mathrm{M}$. tuberculosis, showed higher positivity (77\%) in PCR targeting IS6110 compared to other targets like 65kDa (75\%), 35kDa (72\%) and 85B protein (73\%). Earlier studies reported the positivity of the M. tuberculosis complex by PCR targeting the IS6110 element in specimen wise distribution of the M. tuberculosis complex in EPTB. Tiwari et al., ${ }^{[2]}$ Maurya A K et al., ${ }^{[23]}$ S. Nagesh et al., ${ }^{[26]}$ Portillo - Gomez L, et al., ${ }^{[27]}$ Kolk, AHJ et al., ${ }^{[28]}$ Sekar B et al., ${ }^{[29]}$ showed the detection of the M. tuberculosis complex in the pleural fluid by PCR results as summarized in Table 4. In our study we found 70\% positivity in PCR targeting the IS6110 element in pleural fluid specimens. These data are in agreement with those obtained by Nagesh et al. They reported a sensitivity of $70 \%$ and specificity of $100 \%$. Less sensitivity may arise when the number of samples tested may be low or when the specimens contain very few Mycobacteria. Our studies reveal that the IS6110 based PCR methodology for the detection of the M. tuberculosis complex in the pleural fluid is a highly sensitive, specific and reproducible method for early diagnosis of TPE. 
Table 4:Sensitivity of PCR had shown in various studies

\begin{tabular}{|l|l|}
\hline Reference & Sensitivity \\
\hline Tiwari et.al., 2003 & $56 \%$ \\
\hline Maurya A K et. al., 2012 & $69 \%$ \\
\hline S. Nagesh, Jindal Et. Al., 2001 & $70 \%$ \\
\hline Portillo - Gomez L, Et.Al., 2000 & $94 \%$ \\
\hline Kolk, AHJ et. Al., 1998 & $55.5 \%$ \\
\hline Sekar B et. al., 2008 & $45.8 \%$ \\
\hline
\end{tabular}

\section{Conclusion}

Delay in diagnosis of TPE leads to sequelae as well as spread of infection to other organs. More than one diagnostic procedure is often needed for confirmation of TPE. PCR targeting IS6110 is the simple, rapid and highly sensitive test used in the early diagnosis of TPE. This can be applied when there is strong clinical suspicion, especially when the conventional techniques are negative.

\section{References}

[1]. World Heath Organization: Global tuberculosiscontrol2009: Epidemiology, strategy, financing. Available from [http://www.who.int/tb/publications/global_report/2009/en] Geneva, Switzerland; 2010.WHO/HTM/TB/2009.411 [Last accessed on 2011 Aug 07].

[2]. Sharma SK, Mohan A. Extra pulmonary tuberculosis - Review article. Indian J Med Res 2004; 120:316-53

[3]. Sibley J.C, A study of 200 cases of Tuberculous pleurisy and effusion. Am. Rev.Tuberc 1950; 62; $314-323$.

[4]. Ferrersancho J, Pleural tuberculosis. Incidence, pathogenesis, diagnosis and treatment. Curr. Opin. Pulm. Med. 1996 July 2 (4); 327 -34

[5]. Hawker P M. The role of the polymerase chain reaction in the diagnosis of Mycobacterial infections. Rev Med Microbiol 1994; 4: $21-32$.

[6]. Brisson-Noel A, Lecossier D, Nassif X, Gicquel B, Levy- Frébault V, Hance A J. Rapid diagnosis of tuberculosis by amplification of Mycobacterial DNA in clinical samples. Lancet 1989; ii: 1069-1071.[Pubmed]

[7]. Altamirano M, Kelly M T, Wong A, Bessuille E T, Black W A, Smith J A. Characterization of a DNA probe for detection of Mycobacterium tuberculosis complex in clinical samples by polymerase chain reaction. J ClinMicrobiol 1992; 8: 2173-2176.

[8]. Del Portillo P, Murillo L A, Patarroyo M E. Amplification of a species-specific DNA fragment of Mycobacterium tuberculosis and it's possible use in diagnosis. J ClinMicrobiol 1991; 29: 2163-2168.

[9]. Folgueira L, Delgado R, Palenque E, Noriega A R. Detection of Mycobacterium tuberculosis DNA in clinical samples by using a simple lysis method and polymerase chain reaction. J ClinMicrobiol 1993; 31: 1019-1021.

[10]. Sritharan V, Barker R H. A simple method for diagnosis M.tuberculosis infection in clinical samples using PCR. Mol CellProbes 1991; 5: 385-395.[Pubmed]

[11]. Wilson S M, McNerney R, Nye P M, Godfrey-Faussett P D, Stoker N G, Voller A. Progress toward a simplified polymerase chain reaction and its application to diagnosis of tuberculosis. J ClinMicrobiol 1993; 31: 776-782.

[12]. Topley and Wilson's Microbiology and Microbiol Infections. Gaby E, Pfyffer and Veronique Vincent; $10^{\text {th }}$ Edition, Vol.2 systemic Bacteriology ---- Mycobacterium tuberculosis complex Eds by S. Peter Borriello, Patrick R Murray and Guido Funke Page 1181 -1223, 2005 .

[13]. Venkataraman P, Paramasivan CN. Bacteriological Methods inLaboratory Diagnosis of tuberculosis. Chetput, Chennai, India: Tuberculosis Research Centre (ICMR); 1999.

[14]. Somerville W, Thibert L, Schwartzman K, Behr MA. Extraction of Mycobacterium tuberculosis DNA: A question of containment. J ClinMicrobiol 2005;43:2996-7.

[15]. Eisenach KD, Cave MD, Bates JH, Crawford JT. Polymerase chain reaction amplification of repetitive DNA sequence specific for Mycobacterium tuberculosis. J Infect Dis 1990; 161:977-81.

[16]. Anonymous 1996. Tuberculosis a global emergency - World Health Forum 14. 438.

[17]. Chan C.H.S, Arnold M, Chan C.Y, Mak T.W.L, Hoheisel G B, Clinical and pathological features of Tuberculous pleural of effusion and its long term sequences. Respiration. 1991; 58; $171-175$.

[18]. Babu, S. Nagesh, Shobha, Sehgal, Suinder K, Jindal, Suniel K, Arora et al., Evaluation of PCR for detection of Mycobacterium tuberculosis in pleural fluid. Chest. 2001 Jun; $119(6) ; 1737-1747$.

[19]. Berger H.W, Mejia E, Tuberculous pleurisy. Chest 1973; 63; $88-92$.

[20]. Epstein DM, Kline LR, Albelda SM, Miller WT Tuberculouspleural effusions. Chest 1987; 91:106-09

[21]. Seibert A F, Haynes J, Jr, Middleton R. et alTuberculous pleural effusion. Twenty year experience. Chest 199;.99(4):883-6.

[22]. Tiwari V, Jain A, Verma RK. Application of enzyme amplified Mycobacterial DNA detection in the diagnosis of pulmonary and Extrapulmonary tuberculosis. Indian J Med Res 2003; 118:224-8

[23]. Maurya A K, Kant S, Nag V L, Kushwaha R, Dhole T N. Detection of 123 bp fragment of insertion element IS6110 Mycobacterium tuberculosis for diagnosis of extra pulmonary tuberculosis. Indian J Med Microbiol 2012; 30:182-6

[24]. Negi S S, Anand R, Pasha S T, Gupta S, Basir S F, Khare S, Lal S. Diagnostic potential of IS6110, 38kDa, 65kDa and 85B Sequence-based polymerase chain reaction in the diagnosis of Mycobacterium tuberculosis in clinical samples. Indian J Med Microbiol 2007; 25:43-9

[25]. Patwardhan S A, Bhargava P, Bhide V M, Kelkar D S. A study of tubercular lymphadenitis: A comparison of various laboratory diagnostic modalities with a special reference to tubercular polymerase chain reaction. Indian J Med Microbiol 2011; 29:389-94

[26]. Nagesh B S, Sehgal S, Jindal S K. et al Evaluation of polymerase chain reaction for detection of Mycobacterium tuberculosis in pleural fluid. Chest $2001 ; 119(6): 1737-41$

[27]. Portillo-Gomez, L., S. Morris, and A. Panduro. Rapid and efficient detection of extra-pulmonary Mycobacterium tuberculosis by PCR analysis. Int. J. Tuberc. Lung Dis. 2000; 4:361-370

[28]. Kolk, AHJ, Kox, LFF, van Leeuwen, J, et al Clinical utility of the polymerase chain reaction in the diagnosis of extra pulmonary tuberculosis. EurRespir J 1998; 11:1222-1226

[29]. Sekar B, Selvaraj L, Alexis A, Ravi S, Arunagiri K, Rathinavel L. The utility of IS6110 sequence based polymerase chain reaction in comparison to conventional methods in the diagnosis of extra-pulmonary tuberculosis. Indian J Med Microbiol 2008; 26:352-5 